\title{
The Role of Volume Perfusion CT in the Diagnosis of Pathologies of the Pancreas
}

\section{Die Rolle des Volumenperfusions-CT in der Diagnostik von Pankreaspathologika}

Authors

Affiliation
G. Grözinger, A. Grözinger, M. Horger

Department of Diagnostic and Interventional Radiology, University Hospital Tübingen

\section{Key words}

- abdomen

pancreas

- CT-quantitative

received $\quad 6.2 .2014$

accepted 15.6.2014

\section{Bibliography}

DOI http://dx.doi.org/

10.1055/s-0034-1384876

Published online: 14.8.2014

Fortschr Röntgenstr 2014; 186 :

1082-1093 @ Georg Thieme

Verlag KG Stuttgart · New York .

ISSN 1438-9029

\section{Correspondence}

Herr Dr. Gerd Grözinger

Abteilung für Diagnostische und Interventionelle Radiologie, Universitätsklinik Tübingen Hoppe-Seyler-Str. 3

72076 Tübingen

Germany

Tel.: ++49/7071/2985843

Fax: ++ 49/70 71/295229

gerd.groezinger@med.uni-

tuebingen.de

\section{License terms}

\section{Abstract \\ $\nabla$}

The review discusses the potential role of volume perfusion CT (VPCT) in the diagnosis and follow-up of different pathologies of the pancreas. VPCT enables a differentiation of different pancreatic tumors like adenocarcinoma or neuroendocrine tumors based on functional parameters like blood flow, blood volume and permeability. Furthermore, the article discusses the potential indications for VPCT imaging of inflammatory diseases of the pancreas such as acute or chronic pancreatitis and autoimmune pancreatitis.

Key Points:

- VPCT may help to diagnose even small pancreatic tumors based on functional parameters

- Functional perfusion parameters can help to characterize pancreatic neoplasms

- In acute pancreatitis VPCT can evaluate the perfusion status of the organ

Citation Format:

- Grözinger G., Grözinger A., Horger M. The Role of Volume Perfusion CT in the Diagnosis of Pathologies of the Pancreas. Fortschr Röntgenstr 2014; 186: 1082-1093

\section{Zusammenfassung}

$\nabla$

Der Übersichtsartikel behandelt die mögliche Rolle des Volumenperfusions-CT bei der Diagnostik und der Nachsorge von verschiedenen Pathologien des Pankreas. Das VPCT ermöglicht dabei eine Unterscheidung von verschiedenen Pankreastumoren wie dem Adenokarzinom oder neuroendokrinen Tumoren aufgrund von funktionellen Parametern wie Blutfluss, Blutvolumen und Permeabilität. Des Weiteren diskutiert der Artikel mögliche Indikationen für die VPCT-Bildgebung bei entzündlichen Erkrankungen des Pankreas wie akute oder chronische Pankreatitis und autoimmune Pankreatitis.

\section{Introduction \\ $\nabla$}

Diseases of the pancreas include a broad spectrum of inflammatory and neoplastic diseases. Conventional CT with multiple phases after intravenous contrast agent administration has a firmly established role in primary and differential diagnostics and in aftercare. A multiphase protocol is usually proposed in the literature for specific issues involving the pancreas. Depending on the particular issue, multiple spirals are scanned after one-time contrast agent application. The first spiral is scanned after approx. 20 seconds and corresponds to the early arterial phase which is suitable for example for detecting hypervascularized tumors (e.g., neuroendocrine tumors) [1]. The second spiral begins at $35-40$ seconds (so-called pancreatic phase) with maximum contrast enhancement of the pancreatic parenchyma [2]. The third spiral is scanned in the so-called portal venous phase and is used to evaluate the liver and other organs. However, high sensitivity has been achieved in the diagnosis of pancreatic carcinomas even with monophasic protocols using only one spiral after approx. 65 seconds [3]. Alternatively, spirals are additionally acquired in the so-called equilibrium phase (150 - $180 \mathrm{~s}$ after intravenous contrast agent administration) and are necessary to show vascularization, e.g. of desmoplastic pancreatic carcinomas [4]. Regardless of the number of phases, the common limitation is that the circulation time of patients can vary greatly so that optimum contrast enhancement often cannot be achieved despite bolus tracking [5, 6]. A relatively modern option for expanding conventional CT diagnostic methods to include functional parameters is volume perfusion CT [7, 8]. Depending on the protocol, different tissue parameters are measured thus allowing improved classification of pancreatic lesions in many cases and even allowing estimation of the efficacy of a treatment 
in some cases [9]. The measured parameters are largely independent of the circulation time of the patient in this case. This development is particularly interesting in light of the fact that highly effective targeted treatments are being increasingly developed and tested and conventional follow-up criteria, such as the known RECIST criteria, only reflect the response in the case of new active ingredients on a limited basis [10,11]. A significant change in size is often not to be expected but rather that treatment success is defined exclusively on the basis of a reduction in functional parameters, e.g. perfusion. Thus parameters such as blood flow (BF) and blood volume (BV) seem helpful as surrogate parameters. In addition, the $\mathrm{K}_{\text {trans }}$ (vascular wall permeability) makes it possible to determine an initial estimate of tumor penetration by chemotherapeutic agents and improvement thereof during ongoing modern treatments (e.g. virotherapy) [12].

\section{Volume perfusion CT (VPCT)}

$\nabla$

During VPCT, tissue attenuation is measured after intravenous contrast agent application in the scanned volume. For this purpose, the total organ (tumor) volume is scanned at different points in time. The density in two different ROIs, in an afferent artery and the desired tissue, is compared in the subsequent mathematical analysis [13].

Different mathematical kinetic models are used. The fact that different CT manufacturers offer different software solutions currently makes it difficult to ensure comparability of the measured values and prevents protocol standardization. Therefore, the literature for these perfusion calculation models describes different strengths and weaknesses mainly due to the underlying mathematical models. In addition, interindividual differences in perfusion both of the healthy pancreatic parenchyma and the different pathologies play an important role and greatly complicate the use of cut-off values [14].

A so-called single-compartment analysis (maximum slope) does not differentiate between intravascular space and extravascular space in the target tissue. The perfusion (blood flow, BF) is determined from multiple scans in a short interval. This is calculated using the steepness of the slope during wash-in of the contrast agent in the tissue. The time to maximum density in the tissue (time to peak, TTP) can be determined from the same curve. The time interval between the maximum of the arterial input function and the maximum density increase of the tissue is determined mathematically $[15,16]$. An advantage of this method is that short scan times are sufficient (one breath hold) and information about the venous outflow is not necessary. The high susceptibility to noise and the risk that the arterial peak will be missed in the case of excessive time intervals between scans are a disadvantage.

Two-compartment models which allow for the exchange between the extravascular space and intravascular space and use this to additionally calculate the blood volume (BV) and the permeability (PMB or $\mathrm{K}_{\text {trans }}$ ) in the interstitial phase are primarily used today. The resting blood opposite to perfusion is taken into consideration in the calculation of the blood volume. The two most frequently used models are the Patlak analysis and the so-called deconvolution technique. The deconvolution technique is significantly
Table 1 VPCT imaging parameters.

\begin{tabular}{|l|l|}
\hline parameter & \\
\hline detector configuration (number of rows $\times \mathrm{mm}$ ) & $64 \times 0.6$ \\
\hline tube voltage $(\mathrm{kV})$ & 80 \\
\hline tube load (mAs) & $100-120$ \\
\hline number of measurement points & 26 \\
\hline rotation time (seconds) & 0.5 \\
\hline total time (seconds) & 40 \\
\hline reconstruction algorithm & FBP \\
\hline coverage in Z-axis (cm) & 6.9 \\
\hline radiation exposure in Sv according to [17] (male/female) & $7.0 / 7.1$ \\
\hline
\end{tabular}

less susceptible to noise and is more robust with respect to changes in arterial input function. The underlying mathematical model does not require any assumption about the venous outflow. However, longer acquisition times are needed for two-compartment models (current recommendations are approx. $40 \mathrm{~s}$ ). The applied radiation dose is comparable in both two-compartment models.

Motion correction and filter techniques are additionally used in post-processing in modern protocols. This allows the reconstruction of qualitatively good mean intensity projection (MIP) images even during free breathing of the patient. New equipment allows acquisition of large volumes in the $\mathrm{Z}$-axis due to fast table movement in the so-called shuttle mode (e.g. $50 \mathrm{~cm} / \mathrm{s}$ table advance). Consequently perfusion data for complete organs can be acquired. As a result of its retroperitoneal position, the pancreas offers the advantage that motion artifacts are relatively low compared to other abdominal organs (refer to $\bullet$ Fig. 1).

A possible protocol for the perfusion of the pancreas could be as follows ( Table 1): $80 \mathrm{kV}, 120 \mathrm{mAs}$, collimation $64 \times 0.6 \mathrm{~mm}$ with 26 scans of the target volume with a total acquisition time of $40 \mathrm{~s}$. The additional radiation exposure is approx. $7.0 \mathrm{mSv}$ for normal weight male patients and approx. $7.1 \mathrm{mSv}$ for normal weight female patients [17]. In the future there will be possibilities for reducing dose using iterative reconstruction [18]. A further reduction possibility is provided by new detector technologies which promise a potential dose reduction of $>30 \%[19$, 20].

\section{Use of VPCT in different pathologies of the pancreas \\ $\nabla$}

\section{Adenocarcinoma}

Adenocarcinoma of the pancreas is the most common malignant pancreatic tumor and the third most common tumor of the gastrointestinal tract. Most cases are ductal adenocarcinomas. The tumor typically occurs in the head of the pancreas. CT imaging is used for different issues. The exact size of the tumor is essential for staging. Of particular interest here is vessel invasion of the superior mesenteric artery or vein, celiac trunk, portal vein, or perineural growth. Pancreatic carcinomas are typically hypodense in all CT phases because they appear less perfused compared to the surrounding tissue and histologically often have an extensive desmoplastic reaction [21]. According to pathologists, the vascularization of pancreatic carcinomas should however be strong like most other malignant, fast growing tumors [22]. Increased intratumoral pressure (leakage of the tumor 


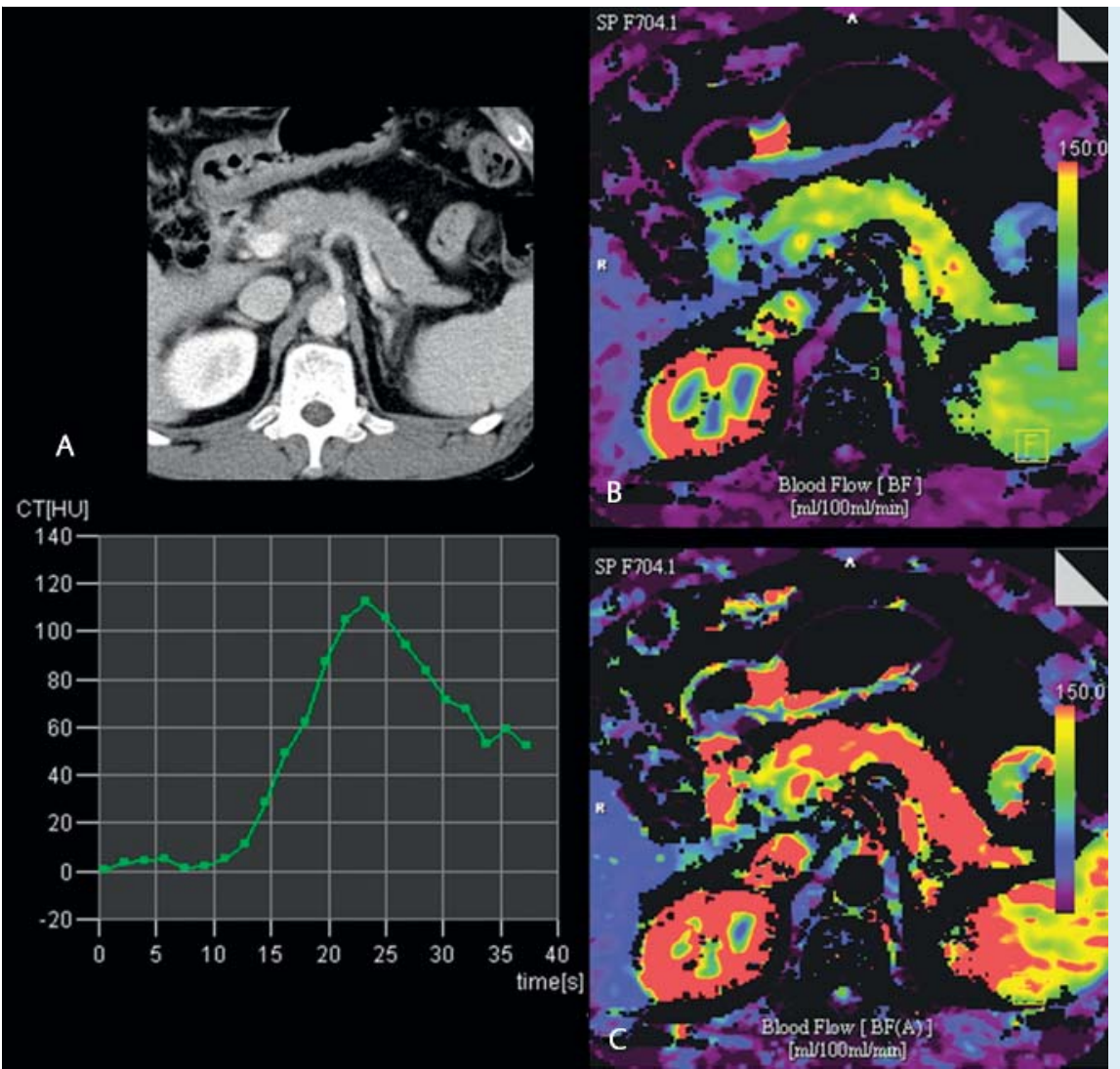

Fig. 1 Healthy pancreas of a 60-year-old patient. (A) Conventional CT image in portal venous phase. Corresponding time-density curve of an ROI in the pancreas head showing a strong wash-in followed by an early wash-out. (B, C) Color maps of the blood flow (BF). Values around $95 \mathrm{ml} / 100 \mathrm{~g} / \mathrm{min}$ ) calculated using the Patlak Method (B) and values around $160 \mathrm{ml} / 100 \mathrm{~g} / \mathrm{min}$ using the deconvolution technique (C). Blood volume (BV) and permeability (PMB) are not displayed with calculated values of $25 \mathrm{ml} / 100 \mathrm{~g}$ and $30 \mathrm{ml} / 100 \mathrm{~g} / \mathrm{min}$, respectively.

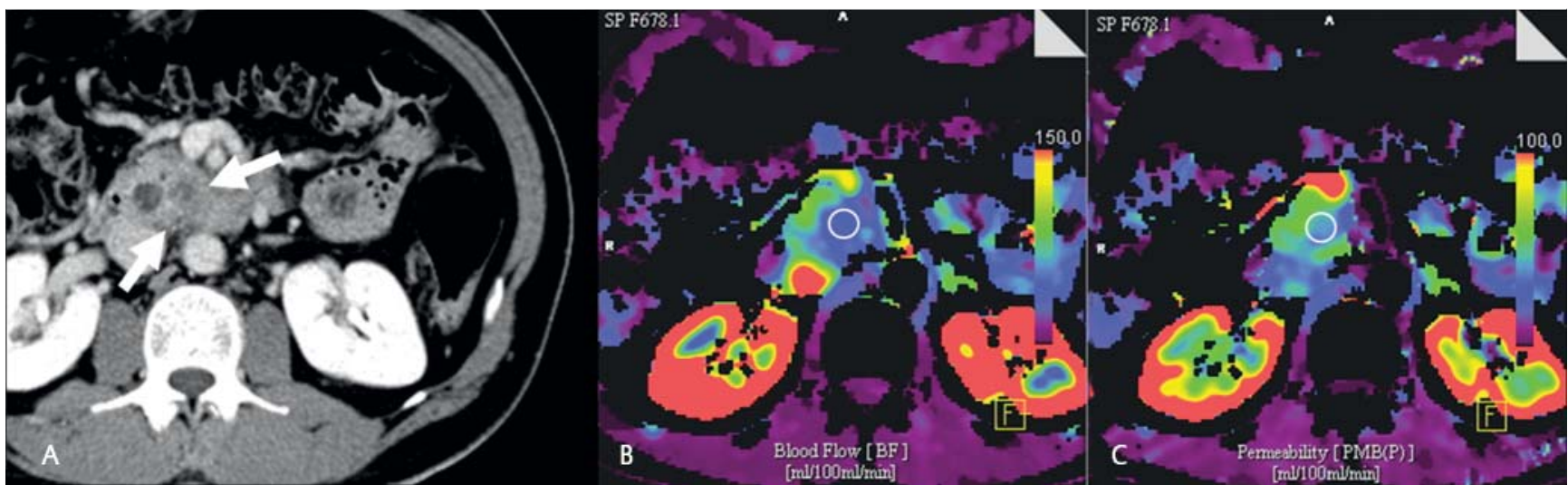

Fig. 2 60-year-old female patient with the typical image of an adenocarcinoma of the pancreas head. The conventional CT shows a hypodense, inhomogeneous mass in the pancreas head (A) accompanied by stasis of the bile duct. The VPCT image shows a significantly reduced BF $(24 \mathrm{ml} / 100 \mathrm{~g} /$ $\mathrm{min}$ ) and BV (not displayed, $3 \mathrm{ml} / 100 \mathrm{~g}$ ). In addition, the permeability was strongly restricted (C). vascular wall) resulting in tumor vessel compression gives the impression of hypovascularization of these tumors in imaging. Pancreatic carcinomas are typically minimally perfused on CE-CT. Nonetheless, up to $11 \%$ of all pancreatic carcinomas are isodense on CT due to better perfusion in the pancreatic phase. In these cases, secondary changes such as duct congestion and changes of the organ contour are the only indications on conventional CT. The VPCT technique can contribute to increasing the sensitivity [21] since primarily isodense carcinomas more clearly show reduced perfusion on VPCT (see $\bullet$ Fig.4). The BF and BV measured in the case of adenocarcinomas are significantly lower than in the surrounding pancreatic tissue ( $\bullet$ Fig. 1a-c, 2a-c). The lowest BF and BV values are typically measured in the center of the tumor. In contrast, significantly higher values are measured in the peripheral zone of the tumor, the zone of active angiogenesis. The values measured here are usually lower than those of the healthy pancreas (blood flow, mean $70-90 \mathrm{ml} / \mathrm{min}^{*} 100 \mathrm{~g}$ according to Patlak analysis or mean $120-140 \mathrm{ml} / \mathrm{min}^{*} 100 \mathrm{~g}$ according to deconvolution technique, see $\bullet$ Table 2). The tissue bordering of the tumor shows perfusion parameters as in healthy tissue with greatly reduced perfusion of the remaining pancreas being able to be detected in some cases of tumor-based atrophy, e.g. in the case of atrophy of the tail of the pancreas due to prolonged duct congestion ( $\bullet$ Fig. 3a-c). Tumor growth, histolo- 


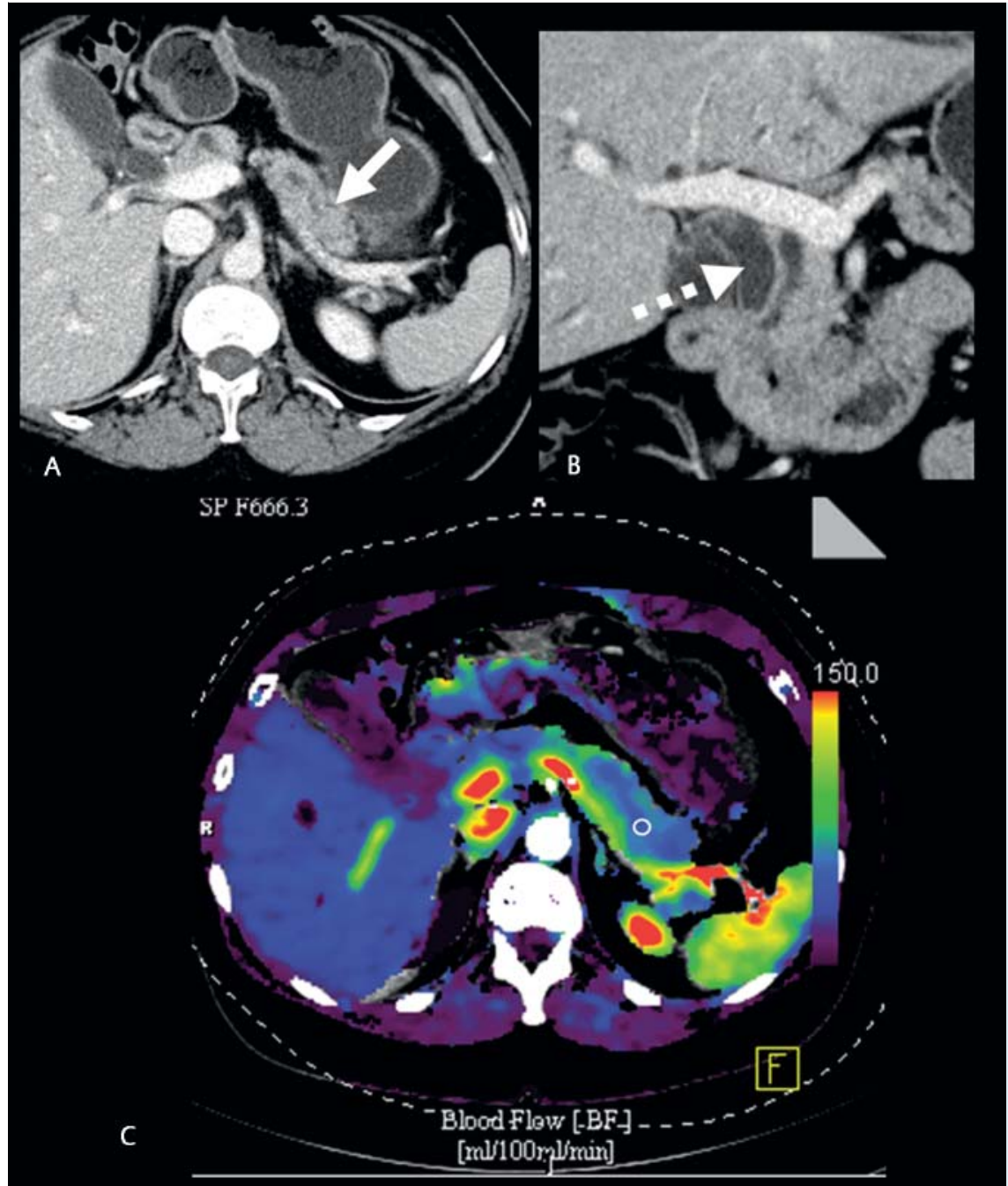

Fig. 3 54-year-old female patient. The conventional $C T$ depicts a cholestasis (dashed line) and slight dilatation of the pancreatic duct (A, B). Conventional $C T$ does not show clear evidence of a pancreatic mass. The pancreatic tissue is isodense without clear signs of atrophy (solid white arrow in A). VPCT however shows a strikingly reduced $B F$ in the tail region (ROI) with a $\mathrm{BF}$ of $52(\mathrm{ml} / 100 \mathrm{~g} / \mathrm{min})$ and a BV of $12(\mathrm{ml} / 100 \mathrm{~g})$. Endoscopy finally revealed an adenocarcinoma of the papilla.

Table 2 Different perfusion parameters in the literature.

\begin{tabular}{|c|c|c|c|c|c|c|}
\hline & study & technique & number & $\begin{array}{l}\text { blood flow (ml/ } \\
100 \mathrm{~g} / \mathrm{min}) \pm S D\end{array}$ & $\begin{array}{l}\text { blood volume } \\
(\mathrm{ml} / 100 \mathrm{~g}) \pm \mathrm{SD}\end{array}$ & $\begin{array}{l}\text { permeability }\left(K_{\text {trans }}\right) \\
(\mathrm{mL} / 100 \mathrm{~g} / \mathrm{min}) \pm S D\end{array}$ \\
\hline \multirow[t]{6}{*}{ normal pancreas } & Delrue et al. [7] & maximum slope & 21 & $77( \pm 13)$ & $16( \pm 2)$ & $28( \pm 14)$ \\
\hline & Motosugi et al. [46] & maximum slope & 20 & 119 & & \\
\hline & Tsushima et al. [47] & maximum-slope & 8 & $88( \pm 42)$ & & \\
\hline & Klauss et al. [21] & Patlak & 25 & $89( \pm 19)$ & $118( \pm 47)$ & $75( \pm 16)$ \\
\hline & d'Assignies et al. [8] & deconvolution & 28 & 130 & 22 & 32 \\
\hline & Xu et al. [48] & deconvolution & 36 & $135( \pm 48)$ & $200( \pm 55)$ & $50( \pm 25)$ \\
\hline \multirow[t]{3}{*}{ adenocarcinoma } & Delrue et al. [24] & maximum slope & 19 & $29( \pm 17)$ & $6( \pm 3)$ & $22( \pm 11)$ \\
\hline & Klauss et al. [21] & Patlak & 25 & $27( \pm 20)$ & $39( \pm 21)$ & $43( \pm 20)$ \\
\hline & Xu et al. [48] & deconvolution & 40 & $29( \pm 21)$ & $60( \pm 37)$ & $38( \pm 29)$ \\
\hline \multirow[t]{2}{*}{ acute pancreatitis } & Delrue et al. [24] & maximum slope & 3 & $49( \pm 15)$ & $9( \pm 4)$ & $23( \pm 6)$ \\
\hline & Bize et al. [49] & maximum slope & 61 & 47 & & 22 \\
\hline chronic pancreatitis & Delrue et al. [24] & maximum slope & 6 & $43( \pm 18)$ & $9( \pm 3)$ & $28( \pm 11)$ \\
\hline \multirow[t]{2}{*}{ neuro-endocrine tumor } & Delrue et al. [24] & maximum slope & 2 & $104( \pm 14)$ & $23( \pm 6)$ & $26( \pm 10)$ \\
\hline & d'Assignies et al. [8] & deconvolution & 36 & 240 & 24 & 55 \\
\hline (pseudo)cystic lesion & Delrue et al. [24] & maximum slope & 3 & $70( \pm 20)$ & $16( \pm 5)$ & $30( \pm 5)$ \\
\hline
\end{tabular}

gical grading, and the progression of pancreatic tumors depend greatly on the angiogenesis. It was possible to show that functional parameters of VPCT can be used to differentiate between high-grade and low-grade tumors on the basis of the blood volume and the maximum enhancement
[23]. Therefore, high-grade tumors generally show low blood volume and low maximum enhancement [23]. Adenocarcinomas of the pancreas usually show reduced permeability $\left(\mathrm{K}_{\text {trans }}\right)$. However, this has not yet been conclusively clarified by the currently available studies $[21,24]$. A 
first study was able to show that $\mathrm{K}_{\text {trans }}$ is a possible surrogate marker for response to radiochemotherapy, with tumors with a low permeability having a significantly worse response to treatment [9]. VPCT can also be helpful for detecting tumors in critical locations (e.g. papilla, periampullary) ( Fig. $4 a-c)$. A comparison with other methods such as diffusion weighting in MRI is not yet available in the literature. However, since CE-CT is the method of choice for diagnosing the pancreas, VPCT could support this method by providing additional functional information.

\section{Cystic and cystic-solid neoplasias of the pancreas}

\section{Serous cystic neoplasia (SCN)}

SCNs are neoplasias that can consist of multiple cysts. A differentiation is made between serous microcystic adenomas, serous macrocystic adenomas, and adenomas associated with Von Hippel-Lindau disease [25]. Microcystic adenomas are the most common variant. As a rule they are benign and are comprised of a central scar with surrounding small cysts [26]. The scar can contain calcifications. Serous oligocystic adenomas are a significantly rarer subtype of serous cystadenoma. They contain fewer larger cysts compared to microcystic adenomas and can be lobulated. They are mainly located in the head of the pancreas. The periphery does not show any contrast agent enhancement while late enhancement was described in the septa [27]. The oligocystic variant is comprised of only a few large cysts while the variant associated with Von Hippel-Lindau consists of multiple cysts distributed across the entire pancreas. The malignant potential of SCNs is generally negligible. Morphological CT/ MRI imaging plays a major role in the differentiation of these subtypes as well as in the delimitation of mucinous cystic pancreatic tumors, for example. The use of VPCT is primarily not necessary but could improve the detection of solid, contrast-enhanced tumor portions, in particular in microcystic variants, due to the numerous measurement points over time, the resolution in the case of fine tumor septa and nodules often being unsuccessful thus incorrectly giving the impression of a solid tumor ( $\bullet$ Fig. 5a-c). In fact, imaging benefits in such cases from the use of T2-weighted MRI sequences that allow better resolution of the septa and the cyst wall and more accurate measurement. Endoscopic ultrasound imaging (EUS) as a more invasive method with comparable diagnostic possibilities is also suitable [28]. New methods, such as through-the-needle imaging with the two options of cystoscopy and confocal laser endomicroscopy, are currently being developed [28]. However, either EUS or MRI is currently recommended for follow-up.

Mucinous cystic neoplasia (MCN) and intraductal papillary mucinous neoplasia (IPMN)

MCNs consist of multilocular large cysts that are primarily located in the tail of the pancreas and affect premenopausal women. Mucinous cystadenomas can appear similar to intraductal papillary mucinous neoplasias (IPMNs) in imaging. However, the lesions are rounded without lobulation and possibly with very fine septa. Solid mural tumor nodules, cyst size $>6 \mathrm{~cm}$, and calcifications are considered signs of malignancy [27]. Papillary tumor segments can be better detected via multiphase CT or VPCT due to the en- hancement. However, as in the case of SCNs, resolution of possible solid segments with VPCT is often not possible here due to the spatial resolution. According to current guidelines, mucinous-cystic neoplasias must be histologically differentiated from IPMNs by detecting ovarian-like stroma. MCNs without a sign of invasion (adenoma) are histologically differentiated from borderline variants and invasive types [29].

The term intraductal papillary mucinous neoplasia (IPMN) includes a series of cystic tumors growing in the main or branch duct of the pancreas [30]. Mixed types were also described [29]. They share papillary differentiation with mucinous secretion. In contrast to other cystic pancreatic lesions, the individual lesions of an IPMN have an irregular configuration [27]. Main duct IPMNs consist of diffuse dilation of the pancreatic duct $(>1 \mathrm{~cm})$ with cystic formations. Solidappearing nodular consolidations are sometimes located in the lesion. IPMNs of the main duct have a high malignant potential and are considered a precursor to ductal pancreatic carcinoma [31].

Side branch IPMNs generally consist of grouped small cysts with a diameter of approx. $1-2 \mathrm{~cm}$. Peripheral cystic lesions can be multilocular but are comprised of a well definable main cyst containing nodular changes or septations. In the case of the mixed variant, the bordering main duct can also be slightly dilated in segments but generally significantly less than in main duct IPMNs.

To date, there is minimal literature about the functional parameters of these lesions. IPMNs are generally minimally vascularized. An additional benefit of the use of functional parameters including perfusion-based data could not yet be proven. As a rule, high-resolution morphological image analysis including tumor matrix evaluation plays a main role in the diagnosis of cystic pancreatic tumors.

\section{Pancreatic endocrine neoplasia (PEN)}

Pancreatic endocrine neoplasias (PENs) represent approx. $1-2 \%$ of all pancreatic tumors. They are primarily well differentiated tumors with preserved endocrine differentiation. Based on the number of mitosis and the proliferation index, the WHO classification (2010) distinguishes between well differentiated PENs (grade 1 and 2) and poorly differentiated endocrine carcinomas (NEC grade 3 ). The further classifications according to AJCC-TNM and ENETS-TNM describe the local tumor extent and distant metastasization with differences in the estimate of the local stage [32]. Additional diagnostic aids are the detection of hormones and biogenic amines and the expression of somatostatin receptors type 2A [33]. Moreover, PENs are divided into functionally active (hormonally active, approx. $40 \%$ ) characterized by a certain clinical picture and non-functionally active (not hormonally active) [34]. Gastrinomas and insulinomas are the most common hormonally active tumors. However, hormone-producing tumors can remain asymptomatic for a relatively long period of time in the case of a low hormone quantity or a lack of effectiveness of the hormones. PENs with a size of less than $0.5 \mathrm{~cm}$ are defined as microadenomas [35]. The prevalence of these microadenomas is specified as up to $10 \%$ [35]. These tumors are asymptomatic and typically do not progress in size. However, all adenomas greater than $0.5 \mathrm{~cm}$ carry the risk of malignant degeneration [35]. The WHO classifies tumors on the basis of size, 

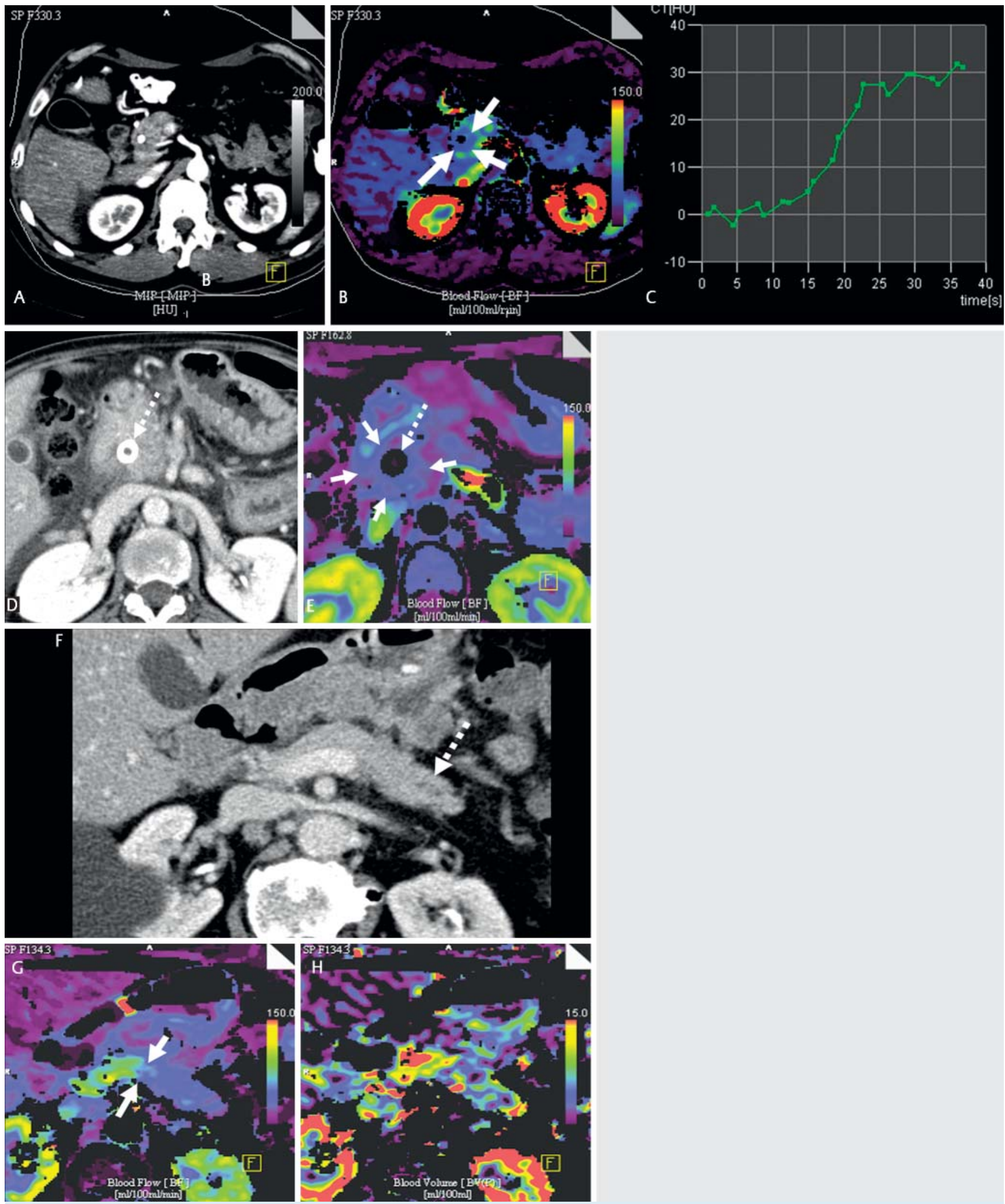

Fig. 4 Examples of the application of VPCT in difficult-to-detect adenocarcinoma. A-C: 63-year-old patient. Periampullary tumor appears isodense (A) with respect to the pancreas on conventional CT. Despite beam-hardening artifacts due to the plastic bile duct prosthesis, a perfusion failure (white arrows in $\mathbf{B}$ ) around the common bile duct is seen as a correlate for the periductally growing isodense adenocarcinoma on VPCT. The typical time-density curve of an adenocarcinoma shows slow wash-in followed by a plateau phase or a further light wash-in (C). D-E: 55-year-old patient. Isodense adenocarcinoma of the head of the pancreas (D). CE-CT shows slight dilation and blurring of the head of the pancreas with retained lobulation. The mass is isodense with respect to the normal pancreas tissue and poorly definable. Condition

after drainage of the common bile duct via the prosthesis (dashed arrow in $\mathbf{D}$ and $\mathbf{E}$ ). VPCT imaging (E) shows significant reduction of the perfusion allowing the tumor to be clearly delimited from the surroundings (white arrows) and showing diffuse infiltration of the head of the pancreas. F-H: Poorly definable adenocarcinoma in the corpus region (F). CE-CT shows no dilation or blurring of the organ contour. Impression of homogeneous perfusion with indication of duct dilation (dashed arrow in $\mathbf{F}$ ). VPCT shows in the perfusion map (G) and blood volume map (H) an abrupt transition from normal perfusion to significantly reduced values (white arrow in $\mathbf{G}$ ). An adenocarcinoma in the duct system could histologically be confirmed. 


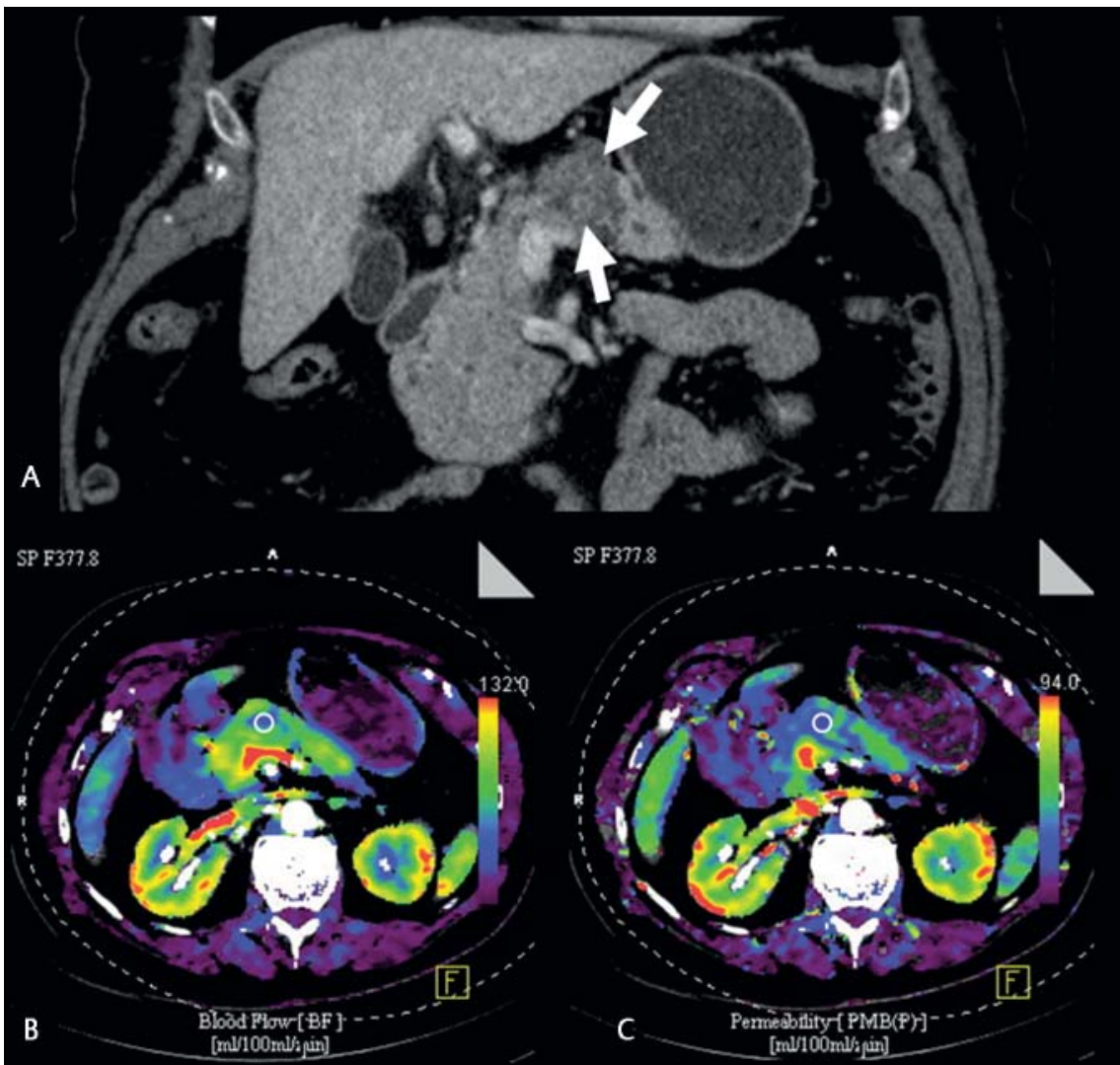

Fig. 5 72-year-old female patient with a cystic tumor (A). After surgical resection the histological diagnosis revealed a microcystic serous cystadenoma. VPCT shows a relatively high BF of $40(\mathrm{ml}$ $100 \mathrm{~g} / \mathrm{min}$ ) (B) and a permeability of $29 \mathrm{ml} / 100 \mathrm{~g} /$ min (C). This finding might be due to partial volume effects. Blood volume of $9(\mathrm{ml} / 100 \mathrm{~g})$ is not displayed.

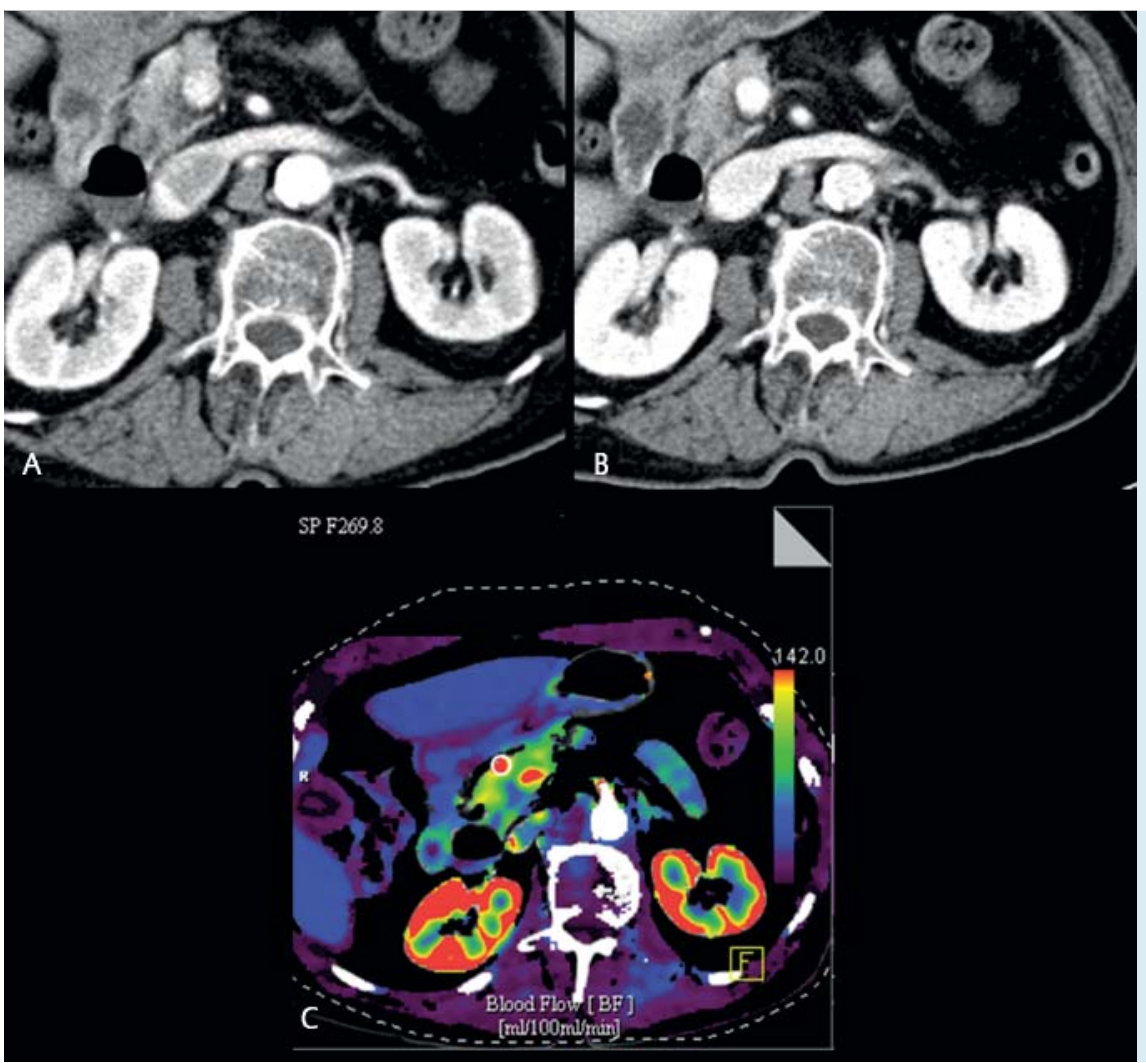

Fig. 6 82-year-old female patient with recurring episodes of hypoglycemia and a pathologic starvation test. Suspicion of an insulinoma. Restricted depiction of the very small lesion in the arterial and portal venous phase (A, B). VPCT (C) shows a strongly increased blood flow (BF $152 \mathrm{ml} / 100 \mathrm{~g} /$ $\mathrm{min})$. Increased blood volume (BV $65 \mathrm{ml} / 100 \mathrm{~g}$ ) and normal permeability ( $K_{\text {trans }} 0.03 \mathrm{ml} / 100 \mathrm{~g} / \mathrm{min}$ ) are not shown.

rate of mitosis, proliferation rate, and invasiveness. Lowgrade or benign tumors tend to grow in an expansive manner while higher-grade tumors grow in an infiltrative manner. All endocrine neoplasias typically have a hyperdense appearance in the arterial phase, the hyperdensity persisting even in the portal venous phase due to the significant vascularization ( $\bullet$ Fig. 6 a-c). In the case of a larger lesion or a cystic appearance, a hypervascularized border is often 

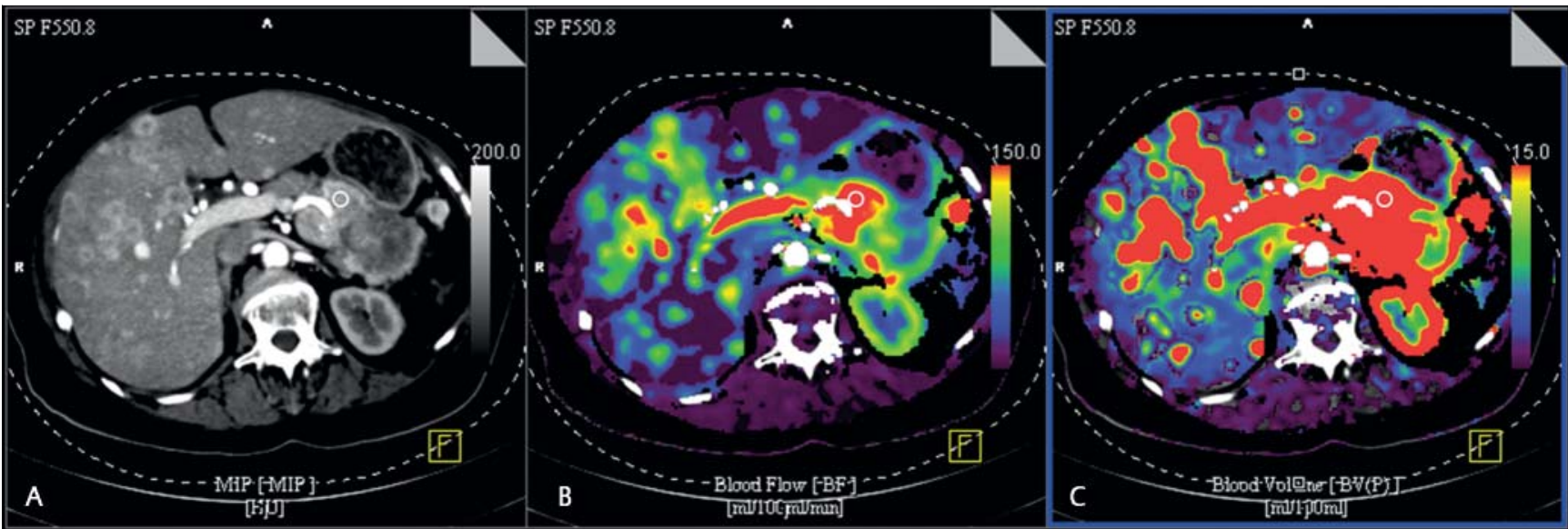

Fig. 7 Non-secretory neuroendocrine tumor with hepatic metastasis. The margin of the primary tumor in the pancreas tail shows strongly increased perfusion with a BF of $160 \mathrm{ml} / 100 \mathrm{~g} / \mathrm{min}$ and a BV of $57 \mathrm{ml} / 100 \mathrm{~g}$. Hepatic

metastases are also markedly hypervascularized. Neoadjuvant therapy can be monitored by the follow-up of the perfusion. seen. Individual tumors can also have a purely cystic appearance. These lesions cannot be reliably differentiated morphologically from other cystic pancreatic lesions via CT. In the case of known PEN, the liver should also be examined with arterial contrast enhancement to rule out hepatic metastasis [35]. In the case of increased perfusion in the peripheral region, this can be missed on conventional CT in a phase-dependent manner. VPCT is helpful in this regard. The smallest PENs can be detected, therefore often making other complementary diagnostic techniques unnecessary such as selective arterial angiography with calcium stimulation and venous sampling. VPCT typically shows increased $\mathrm{BF}$ and $\mathrm{BV}$ values (BF to over $150 \mathrm{ml} / \mathrm{min}^{*} 100 \mathrm{~g}$ [maximum slope model]) compared to the normal pancreas (70$90 \mathrm{ml} / \mathrm{min}^{*} 100 \mathrm{~g}$ according to [maximum slope model])( $\bullet$ Table 2). The hepatic metastases show the same characteristics ( Fig. 7a-c). Initial study results show that the BF is dependent on microcapillarization and histological grading [8]. The BF in well differentiated PENs (WHO grade I) is significantly higher than in high-grade tumors [8]. In the case of endocrine tumors analogously to adenocarcinomas, the prognosis in highly perfused tumors is better than in minimally perfused tumors. For neuroendocrine tumors treated with antiangiogenic agents (bevacizumab), a response to treatment can be shown via VPCT as early as 2 days after the start of treatment [36]. A significant decrease in BF is seen and persists over the course of treatment.

\section{Metastases}

Metastases in the pancreas are relatively rare (in total approx. $2-4 \%$ of all masses of the pancreas). Renal cell carcinomas (approx. 30\%) and bronchial carcinomas are the most common tumors with solitary spread into the pancreas $[37,38]$. The characteristics in imaging are similar to the primary tumor. The tumors are usually significantly better vascularized than adenocarcinomas of the pancreas but are typically less vascularized than the highly vascularized pancreatic parenchyma. However, metastases of renal cell carcinomas in particular can simulate pancreatic PENs due to their high degree of vascularization. In the case of hypervascularized masses of the tail of the pancreas, splenosis or intrapancreatic accessory spleen should be considered as a differential diagnosis. Despite similar BF values, metastases of hypervascularized tumors (RCC, NET) differ from healthy pancreatic parenchyma on corresponding color charts due to different values regarding blood volume, permeability (K $K_{\text {trans }}$ ) or time-to-peak (TTP) (own unpublished data).

\section{Retention cysts}

Retention cysts are usually rounded with a smooth edge and occur as solitary lesions. The cysts are smaller than in side branch IPMNs $(<1 \mathrm{~cm})$. In general, they usually do not present a challenge for differential diagnosis. VPCT does not play a role here.

\section{Acinar cell carcinomas}

Acinar cell carcinomas are rare epithelial neoplasias of the pancreas with acinar differentiation. Although acinar cells represent the majority of the pancreatic tissue, only approx. $1 \%$ of all exocrine pancreatic tumors are acinar cell carcinomas $[37,38]$.

True acinar cell carcinomas typically grow exophytically, oval to round and can be clearly delimited. Tumors are hypodense to isodense on conventional contrast-enhanced CT. In individual cases signs of hypervascularization in imaging are also described ( $\bullet$ Fig. $\mathbf{8 a}-\mathbf{c}$ ). The tumors are typically solid without cystic segments [37]. VPCT can be helpful as an adjunct to normal CE-CT in the detection and delimitation (local staging) of smaller tumors in particular.

\section{Pancreatic lymphoma}

Lymphomas primarily originating from the pancreas are extremely rare (less than $0.5 \%$ of all masses of the pancreas). Lymphomas often grow as a tumor bulk and sheath the vessels without vascular occlusion. As a rule, lymphomas are visualized as solid, homogeneously contrast-enhanced masses. Despite good vascularization, the perfusion parameters of lymphomas only rarely reach values comparable with those of the pancreatic parenchyma and accordingly have mildly low perfusion [39]. 


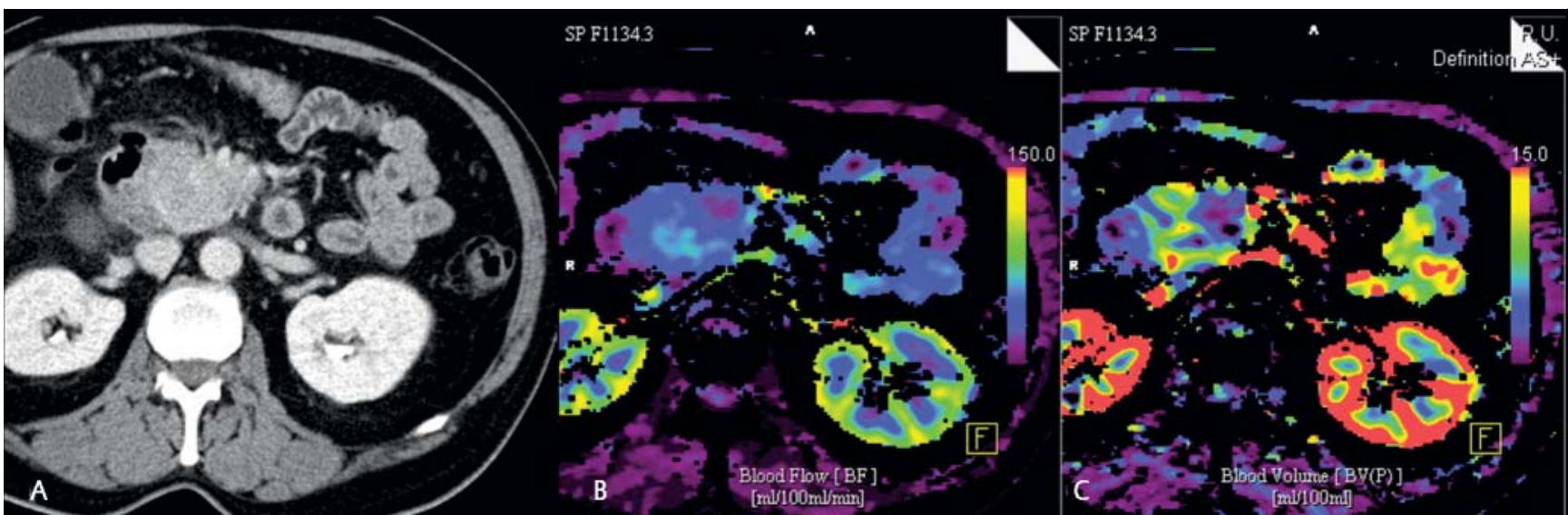

Fig. 8 Images of a 66-year-old patient with initially unclear mass in the pancreas head with relatively homogeneous appearance (A). Histology revealed the diagnosis of an acinar cell carcinoma. Blood flow (B) of $35 \mathrm{ml} / 100 \mathrm{~g} / \mathrm{min}$, blood volume (C) of $3-5 \mathrm{ml} / 100 \mathrm{~g}$.
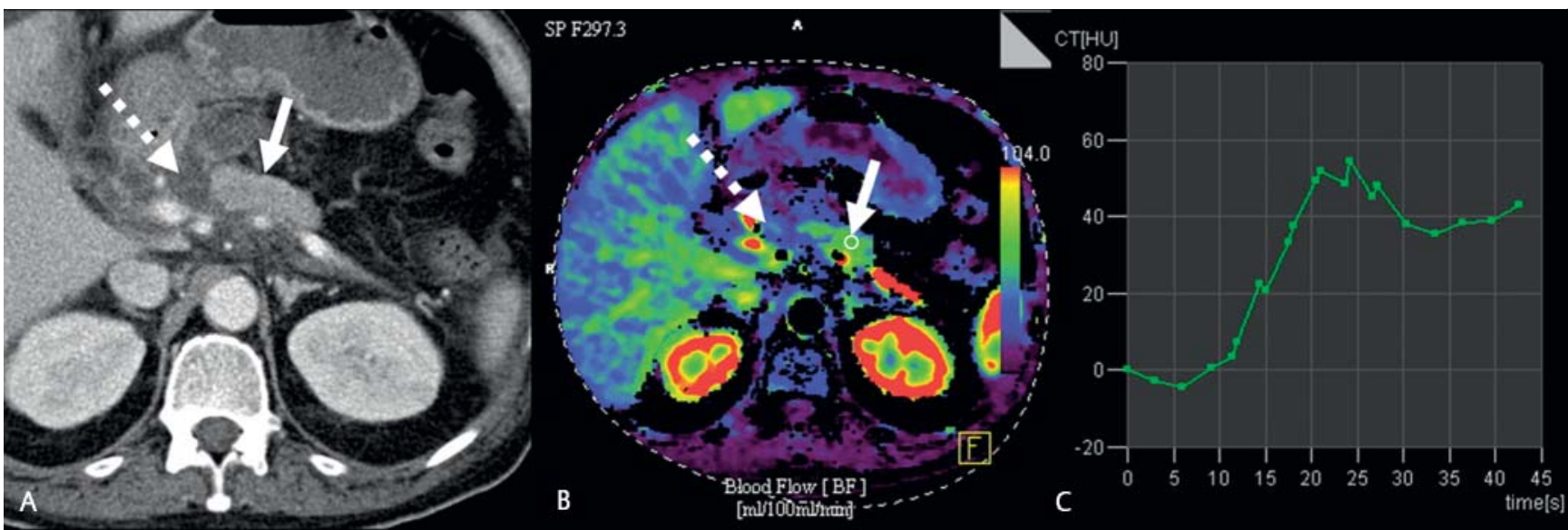

Fig.9 Acute necrotizing pancreatitis of a 51-old-patient with alcohol abuse. Zones in the pancreas head (dashed white arrow in A) display a blood flow under $15 \mathrm{ml} / 100 \mathrm{~g} / \mathrm{min}$ and a blood volume of under $5 \mathrm{ml} / 100 \mathrm{~g}$. The zones with missing perfusion are compatible with necrotic areas. The area is surrounded by free fluid and concurring inflammatory reaction of the sur- rounding fat tissue. The inflamed tissue with edematous changes (solid arrow in $\mathbf{A}$ and $\mathbf{B}$ ) shows reduced BF and BV (BF $56 \mathrm{ml} / 100 \mathrm{~g} / \mathrm{min}, \mathrm{BV} 9 \mathrm{ml} /$ $100 \mathrm{~g}$ ) compared to healthy tissue. In contrast to the continuous wash-in or the plateau phase of the adenocarcinoma, the time-density curve of the pancreatitis shows an early wash-out (C).
Acute and chronic pancreatitis

In the case of pancreatitis, a differentiation must be made between chronic pancreatitis and acute pancreatitis. In both acute and chronic pancreatitis, the measured BF and $\mathrm{BV}$ values are significantly lower than in healthy tissue [24]. The reports about a change in permeability are currently contradictory. The reduced $\mathrm{BF}$ and $\mathrm{BV}$ values can be explained by cellular edema and consequently reduced microperfusion pressure as well as vasospasms [40]. In the case of acute pancreatitis, VPCT helps to identify necroses in the parenchyma and can thus facilitate differentiation from the edematous type ( $\bullet$ Fig. 9a-c). A comparison study of perfusion CT vs. angiography of the hepatic artery showed superiority of CT in the diagnosis of necroses [40]. Necrotic areas have perfusion values close to zero and are therefore in the noise range of the method. Since time-density curves of the corresponding tissue are always determined when acquiring VPCT data, these can be primarily used for analysis [41]. The shape of the time-density curve can be helpful for detecting carcinomas in an organ changed by chronic inflammation. Therefore, chronic inflammation shows a wash-out effect after a minor increase in the timedensity curve ( $\bullet$ Fig.9c). Carcinomas also show an initial slight increase ( $\bullet$ Fig. 10a-c) However, this often ends in a plateau phase or in a further increase in density values [41]. In general, differentiation remains difficult. This also applies to the differentiation of these two pathologies via MRI even using DWI [42].

Rare inflammatory changes and inflammatory pseudotumors

Groove pancreatitis is focal pancreatitis of the head of the pancreas with involvement of the duodenum and common bile duct. It often occurs in alcoholics and can simulate a mass with minimal contrast enhancement. Duct dilation is rare but this pathology can cause small cysts in the duodenal C-loop [38]. A differentiation is made between "pure" and segmental groove pancreatitis [43]. These forms are histologically characterized by scar formation (fibrosis) and hyperplasia of the duodenal glands. Earlier DCE-MRI data have shown delayed and inhomogeneous contrast enhancement in this type of pancreatitis due to the cirrhotic charac- 


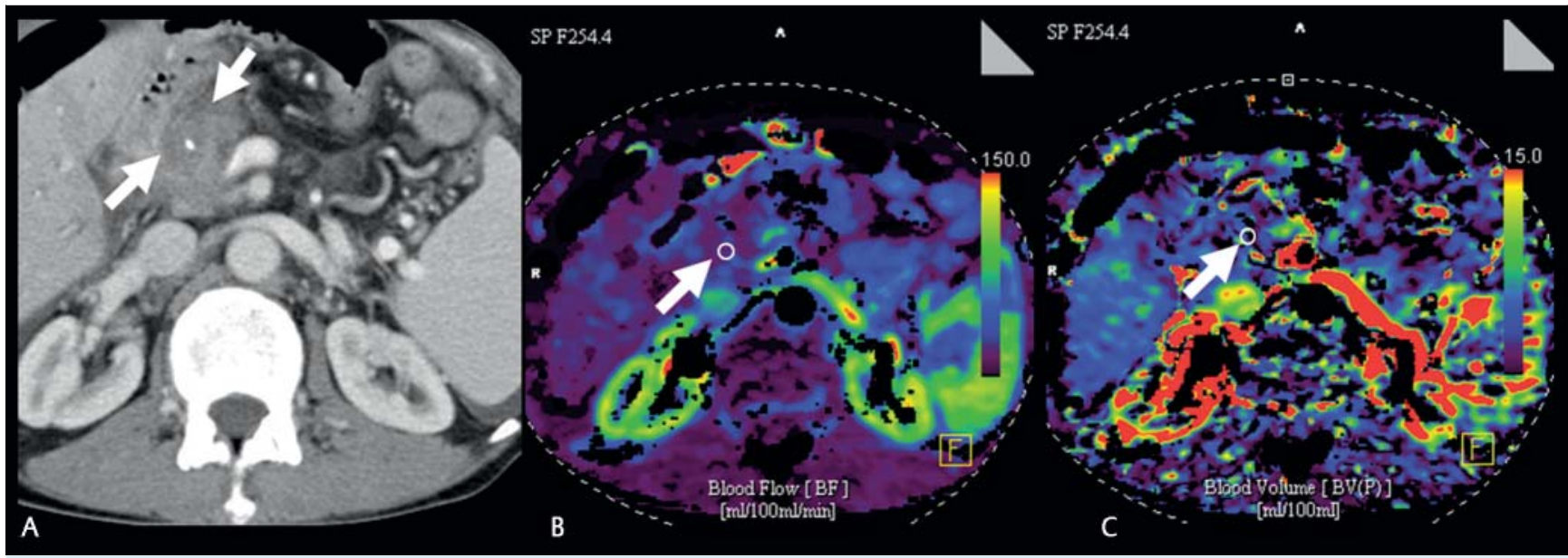

Fig. 10 67-year-old male patient with chronic pancreatitis. The conventional CT (A) shows calcifications of the parenchyma. Reduced perfusion of the pancreas head in the VPCT with a BF of $38 \mathrm{ml} / 100 \mathrm{~g} / \mathrm{min}$ and a BV of $18 \mathrm{ml} / 100 \mathrm{~g}$.

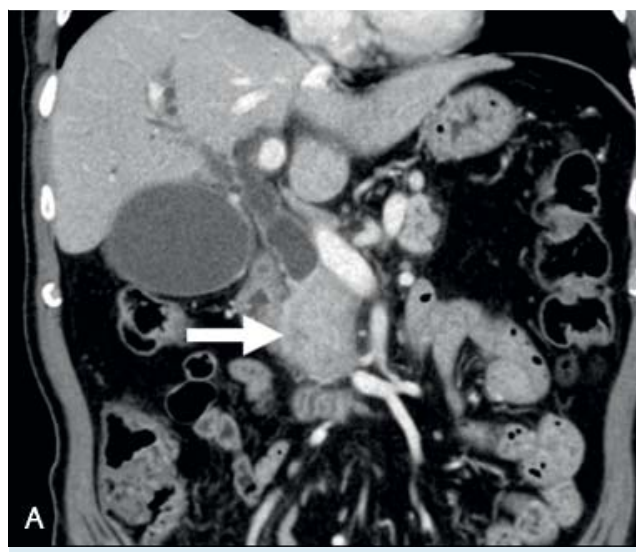

Fig. 11 Pseudotumorous mass in the pancreas head which is isodense compared to the normal pancreas in the portal venous phase (white arrow in $\mathbf{A})$. VPCT imaging (B and $\mathbf{C}$ ) shows a low perfusion and a low blood vol-

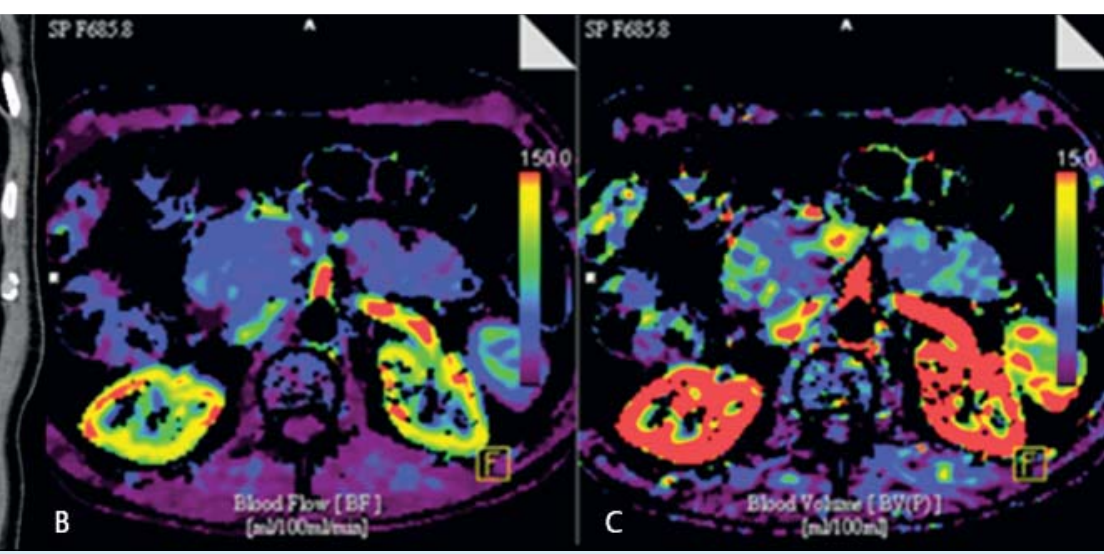

ume (BF $38 \mathrm{ml} / 100 \mathrm{~g} / \mathrm{min}, \mathrm{BV} 4 \mathrm{ml} / 100 \mathrm{~g})$. The suspicion of an $\mathrm{lgG} 4$-associated autoimmune pancreatitis was confirmed. ter of the inflammation [43]. VPCT can detect the type and dynamics of contrast enhancement and thus contribute to characterization. In addition, a VPCT study can be helpful in differentiating between the head of the pancreas and the accompanying cystic duodenal wall transformation.

A further special form of pancreatitis is autoimmune pancreatitis (AIP), also called IgG4-associated sclerosing pancreatitis. CT often shows autoimmune pancreatitis with diffuse or focal organ enlargement with a capsule-like rim, peripancreatic, fine-reticular density increase and rare parenchyma calcifications [38]. Further morphological criteria such as stenoses of the main pancreatic duct $>1 / 3$ of the organ length, focal constrictions, and detection of side branches of the pancreatic duct on the level of the main duct stenoses have proven to be highly suggestive of AIP in differential diagnosis [44]. Organ enlargement is isodense to slightly hypodense with respect to the parenchyma in all phases and peripancreatic inflammatory changes in the fat tissue (halo sign) are often seen. Duct dilation is usually not seen [38]. In the case of diffuse forms, a density comparison to the normal pancreatic parenchyma is however not possible. A comparison of the perfusion values with reference values of a healthy pancreatic parenchyma could be helpful here since AIP is significantly less vascularized (absolute perfusion values) ( $\bullet$ Fig. 11a-c) [45]. In our experience, the measured perfusion values are significantly higher than those of chronic pancreatitis which can be explained by the different histological changes. Atrophy and a further decrease in organ perfusion often occur over time despite proper treatment.

\section{Summary \\ $\nabla$}

Volume perfusion CT of the pancreas can provide useful additional information for a range of issues. Therefore, neuroendocrine tumors with significant perfusion can be effectively differentiated from normal pancreas and adenocarcinomas with low perfusion on the basis of BF and BV. Initial study results indicate that tumor grading via VPCT could be possible and projections regarding treatment response are possible. When evaluating inflammatory changes, VPCT can identify necrotic areas in the parenchyma with great reliability and thus help to decide for or against surgical or interventional treatment. There are currently neither guidelines nor a recognized consensus regarding the use of VPCT in the pancreas. A re- 
quirement for greater use are additional studies involving greater cohorts as well as standardization of protocols and reconstruction algorithms. In the future standardized application of VPCT for the following indications would be conceivable:

1. Pancreatic tumors: Characterization; detection of even small tumors on the basis of perfusion failure (e.g. periampullary carcinomas) or hypervascularization (PENs); treatment monitoring ("targeted" substances, virotherapy, etc.); detection of pancreatic metastases; identification of solid, vascularized tumor segments in primary cystic pancreatic neoplasias vs. cell debris, calcifications, etc.

2. Pancreatitis: Evaluation of organ perfusion (necrosis, hemorrhage); extent of ischemia;

3. Autoimmune diseases: IgG4-AIP-reduced perfusion with respect to normal parenchyma despite normal CE-CT finding.

\section{References}

1 Fidler JL, Fletcher JG, Reading CC et al. Preoperative detection of pancreatic insulinomas on multiphasic helical CT. Am J Roentgenol. American journal of roentgenology 2003; 181: 775-780. DOI: 10.2214/ ajr.181.3.1810775 [published Online First: Epub Date]

2 Boland GW, O'Malley ME, Saez M et al. Pancreatic-phase versus portal vein-phase helical CT of the pancreas: optimal temporal window for evaluation of pancreatic adenocarcinoma. Am J Roentgenol. American journal of roentgenology 1999; 172: 605-608. DOI: 10.2214/ ajr.172.3.10063844 [published Online First: Epub Date]

3 Imbriaco M, Megibow AJ, Ragozzino A et al. Value of the single-phase technique in MDCT assessment of pancreatic tumors. Am J Roentgenol. American journal of roentgenology 2005; 184: 1111-1117. DOI: 10.2214/ajr.184.4.01841111 [published Online First: Epub Date]

4 Tatsumoto S, Kodama Y, Sakurai Y et al. Pancreatic neuroendocrine neoplasm: correlation between computed tomography enhancement patterns and prognostic factors of surgical and endoscopic ultrasound-guided fine-needle aspiration biopsy specimens. Abdominal imaging 2013; 38: 358 - 366. DOI: 10.1007/s00261-012-9953-8 [published Online First: Epub Date]

5 Stafford-Johnson DB, Francis IR, Eckhauser FE et al. Dual-phase helical CT of nonfunctioning islet cell tumors. Journal of computer assisted tomography 1998; 22: 335 - 339

6 Graf O, Boland GW, Warshaw AL et al. Arterial versus portal venous helical CT for revealing pancreatic adenocarcinoma: conspicuity of tumor and critical vascular anatomy. Am J Roentgenol. American journal of roentgenology 1997; 169: 119-123. DOI: 10.2214/ajr.169.1.9207510 [published Online First: Epub Date]

7 Delrue L, Blanckaert P, Mertens D et al. Assessment of tumor vascularization in pancreatic adenocarcinoma using 128 -slice perfusion computed tomography imaging. Journal of computer assisted tomography 2011; 35: 434-438. DOI: 10.1097/RCT.0b013e318223f0c5 [published Online First: Epub Date]

8 d'Assignies G, Couvelard A, Bahrami S et al. Pancreatic endocrine tumors: tumor blood flow assessed with perfusion CT reflects angiogenesis and correlates with prognostic factors. Radiology 2009; 250: 407 416. DOI: 10.1148/radiol.2501080291 [published Online First: Epub Date]

9 Park MS, Klotz E, Kim MJ et al. Perfusion CT: noninvasive surrogate marker for stratification of pancreatic cancer response to concurrent chemo- and radiation therapy. Radiology 2009; 250: 110-117. DOI: 10.1148/radiol.2493080226 [published Online First: Epub Date]

10 Sharma J, Duque M, Saif MW. Emerging therapies and latest development in the treatment of unresectable pancreatic neuroendocrine tumors: an update for clinicians. Therapeutic advances in gastroenterology 2013; 6: 474 -490. DOI: 10.1177/1756283X13498808 [published Online First: Epub Date]

11 Walker EJ, Ко AH. Beyond first-line chemotherapy for advanced pancreatic cancer: An expanding array of therapeutic options? World jour- nal of gastroenterology: WJG 2014; 20: 2224-36 doi: 10.3748/wjg. v20.i9.2224 [published Online First: Epub Date]|

12 Nakao A, Kasuya H, Sahin TT et al. A phase I dose-escalation clinical trial of intraoperative direct intratumoral injection of HF10 oncolytic virus in non-resectable patients with advanced pancreatic cancer. Cancer gene therapy 2011; 18: $167-75$ doi: 10.1038/cgt.2010.65 [published Online First: Epub Date]

13 Petralia G, Preda L, D'Andrea $G$ et al. CT perfusion in solid-body tumours. Part I: Technical issues. La Radiologia medica 2010; 115: 843-857. DOI: 10.1007/s11547-010-0519-y [published Online First: Epub Date]

14 Delrue L, Blanckaert P, Mertens D et al. Variability of CT contrast enhancement in the pancreas: a cause for concern? Pancreatology: official journal of the International Association of Pancreatology 2011; 11: 588-594. DOI: 10.1159/000334547 [published Online First: Epub Date]

15 Miles KA. Perfusion CT for the assessment of tumour vascularity: which protocol? The British journal of radiology 2003, Spec No 176 : S36-S42

16 Miles KA, Charnsangavej C, Lee FT et al. Application of CT in the investigation of angiogenesis in oncology. Academic radiology 2000; 7: 840850

17 Ketelsen $D$, Horger $M$, Buchgeister $M$ et al. Estimation of radiation exposure of 128-slice 4D-perfusion CT for the assessment of tumor vascularity. Korean journal of radiology: official journal of the Korean Radiological Society 2010; 11: 547-552. DOI: 10.3348/kjr.2010.11.5.547 [published Online First: Epub Date]

18 Xie $Q$ Wu J, Tang Y et al. Whole-Organ CT Perfusion of the Pancreas: Impact of Iterative Reconstruction on Image Quality, Perfusion Parameters and Radiation Dose in 256-Slice CT-Preliminary Findings. PloS one 2013; 8: e80468. DOI: 10.1371/journal.pone.0080468 [published Online First: Epub Date]

19 Christe A, Heverhagen J, Ozdoba C et al. CT dose and image quality in the last three scanner generations. World journal of radiology 2013; 5 : 421 - 429 [published Online First: Epub Date] DOI: 10.4329/wjr.v5. i11.421

$20 \mathrm{Li} \mathrm{HO}$, Sun C, Xu ZD et al. Low-dose whole organ CT perfusion of the pancreas: preliminary study. Abdominal imaging 2014; 39: 40-47. DOI: 10.1007/s00261-013-0045-1 [published Online First: Epub Date]

21 Klauss M, Stiller W, Fritz F et al. Computed tomography perfusion analysis of pancreatic carcinoma. Journal of computer assisted tomography 2012; 36: 237 -242. DOI: 10.1097/RCT.0b013e31824a099e [published Online First: Epub Date]

22 Kuehn R, Lelkes PI, Bloechle $C$ et al. Angiogenesis, angiogenic growth factors, and cell adhesion molecules are upregulated in chronic pancreatic diseases: angiogenesis in chronic pancreatitis and in pancreatic cancer. Pancreas 1999; 18: 96-103

23 D'Onofrio M, Gallotti A, Mantovani W et al. Perfusion CT can predict tumoral grading of pancreatic adenocarcinoma. European journal of radiology 2013; 82: 227 - 233. DOI: 10.1016/j.ejrad.2012.09.023 [published Online First: Epub Date]

24 Delrue L, Blanckaert P, Mertens D et al. Tissue perfusion in pathologies of the pancreas: assessment using 128-slice computed tomography. Abdominal imaging 2012; 37: 595-601. DOI: 10.1007/s00261-0119783-0 [published Online First: Epub Date]

25 Buerke B, Heindel W, Wessling J. Differential diagnosis and radiological management of cystic pancreatic lesions. RoFo: Fortschritte auf dem Gebiete der Rontgenstrahlen und der Nuklearmedizin 2010; 182: 852-860. DOI: 10.1055/s-0029-1245502 [published Online First: Epub Date]

26 Itoh S, Ishiguchi T, Ishigaki $T$ et al. Mucin-producing pancreatic tumor: CT findings and histopathologic correlation. Radiology 1992; 183: 81 86. DOI: 10.1148/radiology.183.1.1312735 [published Online First: Epub Date]

27 Kim SY, Lee JM, Kim SH et al. Macrocystic neoplasms of the pancreas: CT differentiation of serous oligocystic adenoma from mucinous cystadenoma and intraductal papillary mucinous tumor. Am J Roentgenol. American journal of roentgenology 2006; 187: 1192-1198. DOI: 10.2214/Am J Roentgenol.05.0337 [published Online First: Epub Date]

28 Nakai $Y$, Isayama H, Itoi T et al. Role of endoscopic ultrasonography in pancreatic cystic neoplasms: Where do we stand and where will we go? Digestive endoscopy: official journal of the Japan Gastroenterological Endoscopy Society 2014; 26: 135-143. DOI: 10.1111/den.12202 [published Online First: Epub Date] 
29 Kloppel G, Kosmahl M. Cystic lesions and neoplasms of the pancreas. The features are becoming clearer. Pancreatology: official journal of the International Association of Pancreatology 2001; 1: 648-655. DOI: 10.1159/000055876 [published Online First: Epub Date]

30 Silas AM, Morrin MM, Raptopoulos $V$ et al. Intraductal papillary mucinous tumors of the pancreas. Am J Roentgenol. American journal of roentgenology 2001; 176: 179-185. DOI: 10.2214/ajr.176.1.1760179 [published Online First: Epub Date]|.

31 Grutzmann R, Post S, Saeger HD et al. Intraductal papillary mucinous neoplasia (IPMN) of the pancreas: its diagnosis, treatment, and prognosis. Deutsches Arzteblatt international 2011; 108: 788-794. DOI: 10.3238/arztebl.2011.0788 [published Online First: Epub Date]

32 Liu TC, Hamilton N, Hawkins $W$ et al. Comparison of WHO Classifications (2004, 2010), the Hochwald grading system, and AJCC and ENETS staging systems in predicting prognosis in locoregional well-differentiated pancreatic neuroendocrine tumors. The American journal of surgical pathology 2013; 37: 853-859. DOI: 10.1097/PAS.0b013e31827fcc18 [published Online First: Epub Date]

33 Anlauf $M$. Neuroendocrine neoplasms of the gastroenteropancreatic system: pathology and classification. Hormone and metabolic research = Hormon- und Stoffwechselforschung $=$ Hormones et metabolisme 2011; 43: 825-831. DOI: 10.1055/s-0031-1291307 [published Online First: Epub Date]

34 Gallotti A, Johnston RP, Bonaffini PA et al. Incidental neuroendocrine tumors of the pancreas: MDCT findings and features of malignancy. Am J Roentgenol. American journal of roentgenology 2013; 200: 355 - 362. DOI: 10.2214/Am J Roentgenol.11.8037 [published Online First: Epub Date]

35 Lewis RB, Lattin GE Jr., Paal E. Pancreatic endocrine tumors: radiologicclinicopathologic correlation. Radiographics: a review publication of the Radiological Society of North America, Inc 2010; 30: 1445-1464. DOI: 10.1148/rg.306105523 [published Online First: Epub Date]

$36 \mathrm{Ng} \mathrm{CS}$, Charnsangavej C, Wei W et al. Perfusion CT findings in patients with metastatic carcinoid tumors undergoing bevacizumab and interferon therapy. Am J Roentgenol. American journal of roentgenology 2011; 196: 569-576. DOI: 10.2214/Am J Roentgenol.10.4455 [published Online First: Epub Date]

37 Raman SP, Hruban RH, Cameron JL et al. Pancreatic imaging mimics: part 2, pancreatic neuroendocrine tumors and their mimics. Am J Roentgenol. American journal of roentgenology 2012; 199: 309-318. DOI: 10.2214/Am J Roentgenol.12.8627 [published Online First: Epub Date]

38 Coakley FV, Hanley-Knutson K, Mongan J et al. Pancreatic imaging mimics: part 1, imaging mimics of pancreatic adenocarcinoma. Am J Roentgenol. American journal of roentgenology 2012; 199: 301 - 308. DOI: 10.2214/Am J Roentgenol.11.7907 [published Online First: Epub Date]

39 Spira $D$, Adam $P$, Linder $C$ et al. Perfusion and flow extraction product as potential discriminators in untreated follicular and diffuse large B cell lymphomas using volume perfusion CT with attempt at histopathologic explanation. Am J Roentgenol. American journal of roentgenology 2012; 198: 1239-1246. DOI: 10.2214/Am J Roentgenol.11.7858 [published Online First: Epub Date]

40 Tsuji Y, Hamaguchi K, Watanabe Y et al. Perfusion CT is superior to angiography in predicting pancreatic necrosis in patients with severe acute pancreatitis. Journal of gastroenterology 2010; 45: 1155-1162. DOI: 10.1007/s00535-010-0267-8 [published Online First: Epub Date]

41 Zamboni GA, Bernardin L, Pozzi MucelliR. Dynamic MDCT of the pancreas: is time-density curve morphology useful for the differential diagnosis of solid lesions? A preliminary report. European journal of radiology 2012; 81: e381-e385. DOI: 10.1016/j.ejrad.2011.11.055 [published Online First: Epub Date]

42 Sandrasegaran $K$, Nutakki K, Tahir B et al. Use of diffusion-weighted MRI to differentiate chronic pancreatitis from pancreatic cancer. Am J Roentgenol. American journal of roentgenology 2013; 201: 1002 1008. DOI: 10.2214/Am J Roentgenol.12.10170 [published Online First: Epub Date]

43 Blasbalg $R$, Baroni RH, Costa DN et al. MRI features of groove pancreatitis. Am J Roentgenol. American journal of roentgenology 2007; 189 : 73-80. DOI: 10.2214/Am J Roentgenol.06.1244 [published Online First: Epub Date]

44 Shin JU, Lee JK, Kim KM et al. The differentiation of autoimmune pancreatitis and pancreatic cancer using imaging findings. Hepato-gastroenterology 2013; 60: 1174 -1181. DOI: 10.5754/hge11946 [published Online First: Epub Date]

45 Takahashi N, Fletcher JG, Fidler JL et al. Dual-phase CT of autoimmune pancreatitis: a multireader study. Am J Roentgenol. American journal of roentgenology 2008; 190: 280 -286. DOI: 10.2214/Am J Roentgenol.07.2309 [published Online First: Epub Date]

46 Motosugi U, Ichikawa T, Sou $\mathrm{H}$ et al. Multi-organ perfusion CT in the abdomen using a 320-detector row CT scanner: preliminary results of perfusion changes in the liver, spleen, and pancreas of cirrhotic patients. European journal of radiology 2012; 81: 2533-2537. DOI: 10.1016/j.ejrad.2011.11.054 [published Online First: Epub Date]

47 Tsushima Y, Miyazaki M, Taketomi-Takahashi A et al. Feasibility of measuring human pancreatic perfusion in vivo using imaging techniques. Pancreas 2011; 40: 747-752. DOI: 10.1097/MPA.0b013e318215ac22 [published Online First: Epub Date]

$48 \mathrm{Xu}$ J, Liang Z, Hao S et al. Pancreatic adenocarcinoma: dynamic 64-slice helical CT with perfusion imaging. Abdominal imaging 2009; 34: 759 766. DOI: 10.1007/s00261-009-9564-1 [published Online First: Epub Date]

49 Bize PE, Platon A, Becker CD et al. Perfusion measurement in acute pancreatitis using dynamic perfusion MDCT. Am J Roentgenol. American journal of roentgenology 2006; 186: 114-118. DOI: 10.2214/Am J Roentgenol.04.1416 [published Online First: Epub Date] 